\title{
Different impact of calreticulin mutations on human hematopoiesis in myeloproliferative neoplasms
}

\author{
Mira El-Khoury ${ }^{1,2,3} \cdot$ Xénia Cabagnols $^{1,2,3} \cdot$ Matthieu Mosca ${ }^{1,2,4} \cdot$ Gaëlle Vertenoeil $^{5,6} \cdot$ Christophe Marzac $^{7}$. \\ Fabrizia Favale $^{8}$. Olivier Bluteau ${ }^{1,2,4}$. Florence Lorre ${ }^{8}$ - Amandine Tisserand ${ }^{1,2,3}$. Graciela Rabadan Moraes ${ }^{1,2,3}$. \\ Valérie Ugo ${ }^{9}$ Jean-Christophe lanotto ${ }^{10}$ - Jerôme Rey ${ }^{11}$. Eric Solary ${ }^{1,2,4,7} \cdot$ Lydia Roy $^{12} \cdot$ Philippe Rameau $^{2}$. \\ Najet Debili ${ }^{1,2,4}$. Florence Pasquier ${ }^{1,2,4,7} \cdot$ Nicole Casadevall ${ }^{1,2,13}$. Caroline Marty ${ }^{1,2,4}$. \\ Stefan N. Constantinescu $\mathbb{D}^{5,6,14} \cdot$ Hana Raslova ${ }^{1,2,4} \cdot$ William Vainchenker $\mathbb{D}^{1,2,4} \cdot$ Isabelle Plo $\mathbb{D}^{1,2,4}$
}

Received: 11 December 2019 / Revised: 5 June 2020 / Accepted: 11 June 2020 / Published online: 22 June 2020

(c) The Author(s), under exclusive licence to Springer Nature Limited 2020

\begin{abstract}
Mutations of calreticulin (CALRm) define a subtype of myeloproliferative neoplasms (MPN). We studied the biological and genetic features of $C A L R$-mutated essential thrombocythemia and myelofibrosis patients. In most cases, CALRm were found in granulocytes, monocytes, B and NK cells, but also in T cells. However, the type 1 CALRm spreads more easily than the type $2 C A L R m$ in lymphoid cells. The CALRm were also associated with an early clonal dominance at the level of hematopoietic stem and progenitor cells (HSPC) with no significant increase during granulo/monocytic differentiation in most cases. Moreover, we found that half of type 2 CALRm patients harbors some homozygous progenitors. Those patients were associated with a higher clonal dominance during granulo/monocytic differentiation than patients with only heterozygous type $2 C A L R m$ progenitors. When associated mutations were present, $C A L R m$ were the first genetic event suggesting that they are both the initiating and phenotypic event. In blood, type $1 C A L R m$ led to a greater increased number of all types of progenitors compared with the type 2 CALRm. However, both types of CALRm induced an increase in megakaryocytic progenitors associated with a ruxolitinib-sensitive independent growth and with a mild constitutive signaling in megakaryocytes. At the transcriptional level, type 1 CALRm seems to deregulate more pathways than the type 2 $C A L R m$ in megakaryocytes. Altogether, our results show that CALRm modify both the HSPC and megakaryocyte biology with a stronger effect for type 1 than for type 2 CALRm.
\end{abstract}

These authors contributed equally: William Vainchenker, Isabelle Plo

Supplementary information The online version of this article (https:// doi.org/10.1038/s41388-020-1368-3) contains supplementary material, which is available to authorized users.

William Vainchenker

william.vainchenker@gustaveroussy.fr

$\triangle$ Isabelle Plo

isabelle.plo@gustaveroussy.fr

1 INSERM, UMR1287, Villejuif, France

2 Gustave Roussy, Villejuif, France

3 Université Paris Diderot (Paris 7), UMR1287, Gustave Roussy, Villejuif, France

4 Université Paris XI, UMR1287, Gustave Roussy, Villejuif, France

5 Ludwig Institute for Cancer Research Brussels, Brussels, Belgium

6 Université Catholique de Louvain and de Duve Institute, Brussels, Belgium
Département d'Hématologie, Gustave Roussy, Villejuif, France

8 Sorbonne Université, INSERM, Centre de Recherche SaintAntoine, CRSA, UMR_S 938, Paris, France

9 CHU Angers, Laboratoire d'Hématologie, Angers, France

10 CHRU Brest, service d'Hématologie, Brest, France

11 Département d'Hématologie, Institut Paoli Calmettes, Service d'Hématologie, Marseille, France

12 Assistance Publique Hôpitaux de Paris, CHU Henri Mondor, Service d'Hématologie, Créteil, France

13 Laboratoire d'Hématologie, Hôpital Saint Antoine, Assistance Publique Hôpitaux de Paris, Paris, France

14 WELBIO (Walloon Excellence in Life Sciences and Biotechnology), Brussels, Belgium 


\section{Introduction}

Classical $B C R-A B L 1$-negative myeloproliferative neoplasms (MPN) include essential thrombocythemia (ET), polycythemia vera (PV) and primary myelofibrosis (PMF). They are clonal hematopoietic diseases due to a defect at the level of hematopoietic stem cells (HSC) that leads to an excess of myeloid cells. Presently, there are three main drivers in MPN. JAK2V617F is present in $60 \%$ of ET and PMF and in $95 \%$ of PV $[1,2]$. Several thrombopoietin receptor $(M P L)$ mutations have been identified in $5-10 \%$ of ET and PMF [3-5]. Around 50 different mutations in calreticulin $(C A L R m)$ were reported in $25-30 \%$ of ET and PMF [6, 7].

All CALRm induce a frameshift $(+1)$, leading to a new quasi-identical positively charged C-terminal peptide and the loss of the KDEL sequence. The main difference between these mutations is the size of the residual normal sequence of the exon 9. The most recurrent mutations are CALRdel52 type 1 and CALRins5 type 2 mutations accounting for around $50 \%$ and $40 \%$ of ET and $80 \%$ and $10 \%$ of PMF, respectively $[8,9]$. All other mutations are responsible for $10 \%$ of ET and $20 \%$ of PMF and have been classified into type 1-like and type 2-like based on the absence or presence of a residual wild-type calcium-binding motif and the modification of the $\alpha$-helix structure $[10,11]$. Several studies, including ours, have shown that CALR mutants activate the JAK2/STAT signaling pathway through the binding and the activation of MPL [12-15]. Moreover, retroviral mouse models after transduction of bone marrow to express either CALRdel52 or CALRins5 recapitulated the thrombocytosis with a much more severe phenotype for the CALRdel52 mutant that led to a MF progression [15]. More recently, CALRdel52 transgenic and knock-in (KI) mouse models have been generated. All of them lead to a moderate thrombocytosis without MF except a chimeric (mouse/human) CALR KI that showed a thrombocytosis progressing to MF [16-18].

There is strong evidence that $J A K 2 V 617 F$ and $C A L R m$ define two different disorders with different outcomes. In contrast to CALRm, JAK2V617F disease occurs nearly 10 years later and patients present lower platelet counts, increased neutrophil counts, hemoglobin levels, and risk of thrombosis [19-21]. However, there are clinical differences between type 1 and type 2 CALRm. Type 2 mutations lead to ET with higher platelet counts than type 1 mutations, but are rare in PMF in contrast to type 1 mutations $[8,11,19,22]$. There is also evidence that the variant allele frequency (VAF) of CALRm in granulocytes of ET is much higher than that of JAK2V617F suggesting that $C A L R m$ lead to a greater clonal dominance to induce a disease $[6,7,21]$.

Here, we extensively studied the biological and genetic features of $C A L R$-mutated ET and PMF patients on hematopoiesis.
Particularly, we evaluated the effects of type 1 and type 2 $C A L R m$ on clonal dominance and amplification of the hematopoietic stem and progenitor cells (HSPC) as well as their clonal advantage during myeloid and lymphoid differentiation. In addition, we carefully evaluated the role of the two different $C A L R m$ on the generation of megakaryocyte (MK) progenitors and the signaling and gene expression profiles in MK.

\section{Results}

\section{CALRm are present in blood myeloid and lymphoid cells}

We studied $C A L R m$ by fragment sizing in 24 patients including 11 type 1 and type 1-like (called type 1 ) and 13 type 2, and type 2-like (called type 2) patients, with the initial diagnosis of ET or PMF [23]. As shown in Fig. 1a, b, the VAF was high and similar in granulocytes and monocytes (27-55\% VAF) whatever the type of CALRm or the nature of the disease (ET and MF). One exception was CALRdel16 P52 patient, who presents a familial history (family including 4 MPN cases) and harbors an exceptionally low CALRm VAF. Lymphoid cells including NK cells $\left(\mathrm{CD} 56^{+} \mathrm{CD} 14^{-}\right)$, B cells $\left(\mathrm{CD} 19^{+}\right)$and $\mathrm{T}$ cells $\left(\mathrm{CD} 3{ }^{+} \mathrm{CD} 19^{-} \mathrm{CD} 56^{-} \mathrm{CD} 14^{-}\right)$were sorted and obtained with a purity over $93 \%$ (Figs. S1 and S2). CALRm could be detected in all these populations including the $\mathrm{CD}^{+}$cells (P30, P48, P151, P38, P28, P50, P54, and P80). The VAF was low but could reach $18 \%$ excluding that this could be due to a contamination. Moreover, we observed significant different VAF between granulocytes or $\mathrm{CD} 14^{+}$cells and $\mathrm{CD}^{+}$cells for both types of CALR $m$ mutations. However, VAF between granulocytes or $\mathrm{CD} 14^{+}$cells and $\mathrm{CD} 19^{+}$ cells and VAF between $\mathrm{CD} 56^{+}$and $\mathrm{CD} 3^{+}$were only found significantly different for $C A L R$ type $2 \mathrm{ET}$, suggesting a lower advantage in $\mathrm{B}$ and $\mathrm{T}$ cells of $C A L R$ type 2 than CALR type 1 (Fig. 1c).

These results show that the $C A L R$ type 1 and, to a lesser extent, $C A L R$ type 2 are present in all the hematopoietic cells including the myeloid, but also the lymphoid cell compartments. These results suggest an early clonal amplification by CALRm in lympho/myeloid progenitors.

\section{CALRm are present in hematopoietic progenitors}

To directly demonstrate the role of CALRm in early clonal amplification, we purified the hematopoietic progenitors $\left(\mathrm{CD} 34^{+}\right)$from peripheral blood and sorted into $\mathrm{CD} 34^{+}$ $\mathrm{CD} 38^{-} \mathrm{CD} 90^{+}$(HSC-enriched progenitors), $\mathrm{CD} 34^{+} \mathrm{CD} 38^{-}$ $\mathrm{CD}^{-} 0^{-}$(multipotent progenitors) and $\mathrm{CD} 34^{+} \mathrm{CD} 38^{+}$ $\mathrm{CD}^{-} 0^{-}$(committed progenitors) cell fractions. When the number of $\mathrm{CD}_{3} 4^{+}$cells was low, cells were separated only 

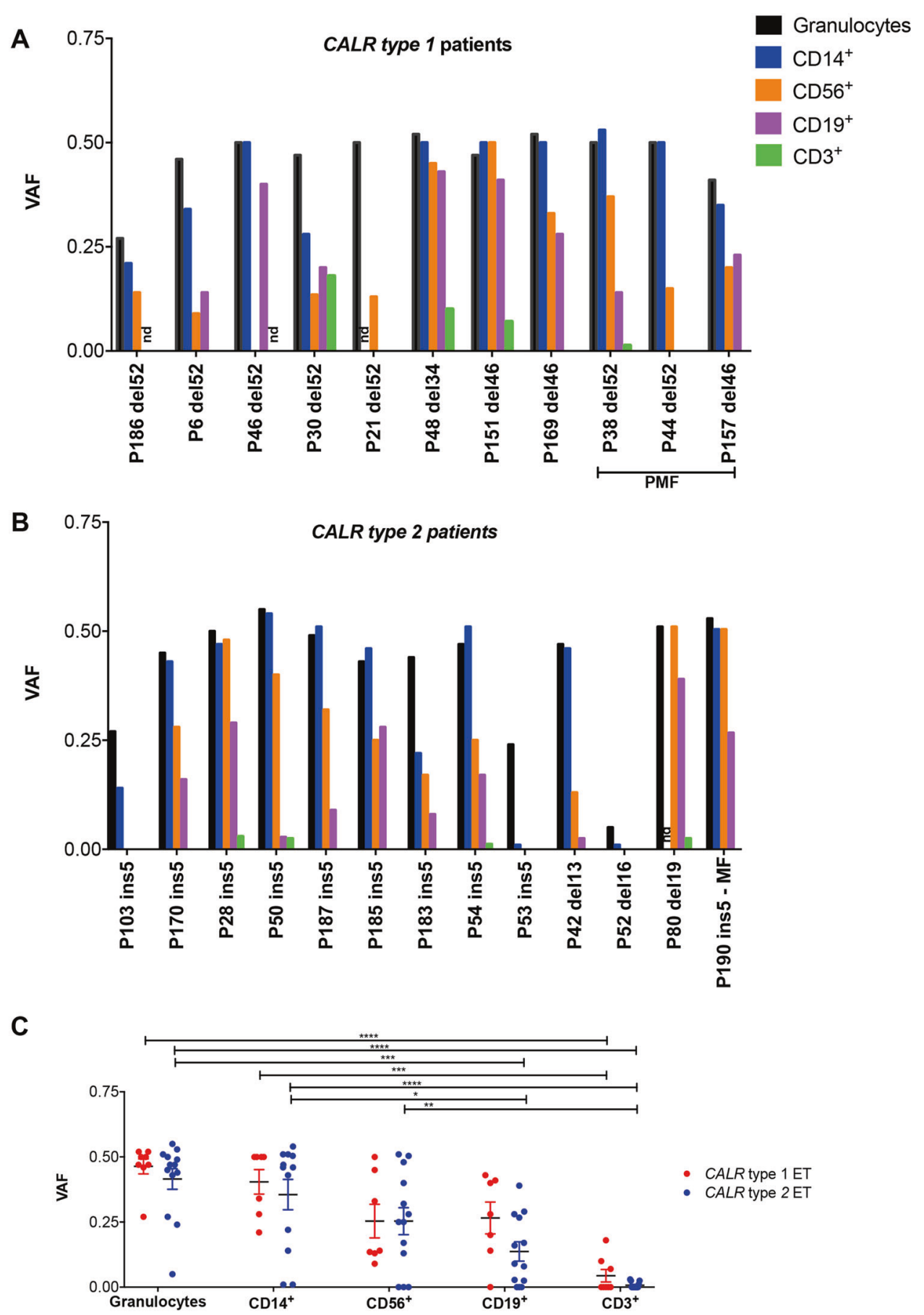

Fig. 1 CALRm are present in all hematopoietic cells. CALR variant allele frequencies (VAF) in granulocytes, CD14 ${ }^{+}, \mathrm{CD}^{+} 6^{+}, \mathrm{CD} 19^{+}$, and $\mathrm{CD}^{+}$cells isolated from peripheral blood of ET or MF patients with type 1 or type 2 mutations. a CALR type 1 mutations (including del52, del46, del34), VAF were measured in DNA extracted from blood cells of 11 patients (8 ET and $3 \mathrm{PMF}$ ) using fragment sizing. VAF were $0 \%$ in CD3 ${ }^{+}$ cells of P186, P6, P183, P46, P42, P169, P157, and P21. The following samples were not done (nd) for CD19 ${ }^{+}$of P186, CD56 ${ }^{+}$of P46, and $\mathrm{CD}_{14}^{+}$of P21. b CALR type 2 mutations (including ins 5, del13, del16, and del19), VAF were measured in DNA extracted from blood cells of 12 ET and 1 MF patients using fragment sizing. VAF were $0 \%$ in $\mathrm{CD}^{+}$cells of P103, P170, P187 and P185, P52, P53, P80. The following sample was not done (nd) for $\mathrm{CD} 14^{+}$of $\mathrm{P} 80$ patient. c CALR type 1 and type 2 mutation VAF were calculated for ET patients in the different hematopoietic cells. Results are the mean \pm SEM $(* * P<0.01 ; * * * P<0.001 ; * * * P<0.0001$ Tukey's multiple comparisons test).

into $\mathrm{CD} 34^{+} \mathrm{CD} 38^{-}$and $\mathrm{CD} 34^{+} \mathrm{CD} 38^{+}$cell fractions. The clonal architecture of these fractions was studied after 14 days of culture of single cells directly cloned by cell sorting in serum-free medium with cytokines. Therefore, all cell fractions were submitted to a double round of cell sorting leading to a purity over $97 \%$. We studied 19 patients 
Fig. $2 C A L R m$ harbor a high clonal dominance at the progenitor cell level. Clonal architecture was studied in stem cells-enriched progenitors $\left(\mathrm{CD} 34^{+} \mathrm{CD} 38^{-} \mathrm{CD} 90^{+}\right.$), multipotent progenitors (CD34 $\left.{ }^{+} \mathrm{CD} 38^{-} \mathrm{CD} 90^{-}\right)$and committed progenitors $\left(\mathrm{CD} 34^{+} \mathrm{CD} 38\right.$

$\left.{ }^{+} \mathrm{CD} 90^{-}\right)$. Cells were cultured at single cell level in serum-free medium with cytokines for 14 days. Each colony was genotyped by conventional PCR or qPCR analysis for 7 ET or 3 PMF CALR type 1-mutated patients (a), and 9 CALR type 2mutated patients (b) and the percentages of each genotype are indicated. The number of genotyped colonies are indicated in Table S3. c CALR type 1 and type 2 mutation VAF were calculated for ET patients in the different hematopoietic progenitors. Results are the mean \pm SEM (no significant differences by Tukey's multiple comparisons test).
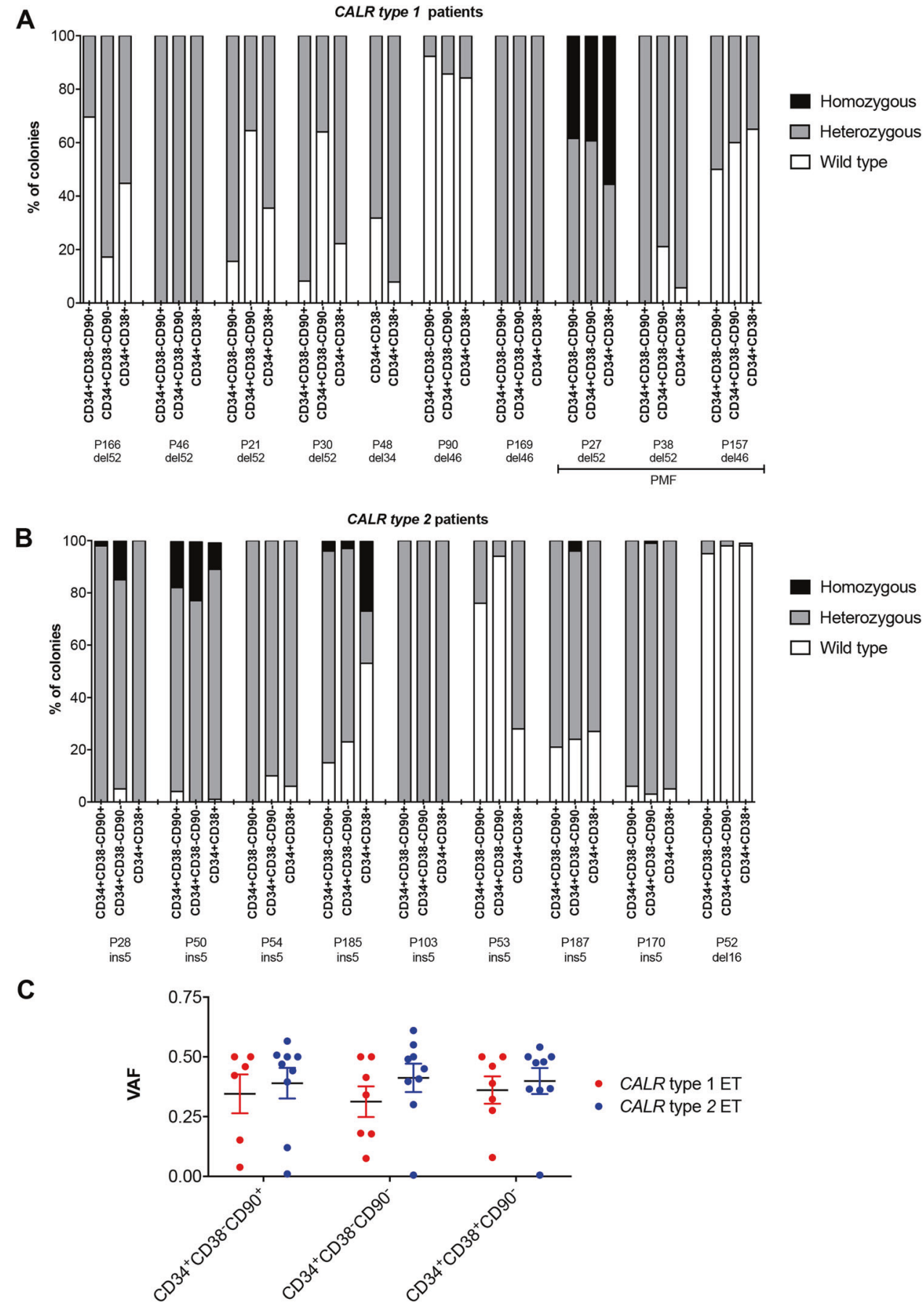

including 10 with CALRm type 1 and 9 with CALRm type 2 . Overall, the cloning efficiency was high in all fractions (mean of $70 \%$ in $\mathrm{CD} 34^{+} \mathrm{CD} 38^{+} \mathrm{CD} 90^{-}, 59 \%$ in $\mathrm{CD} 34^{+}$ $\mathrm{CD} 38^{-} \mathrm{CD} 90^{-}$, and $60 \%$ in $\mathrm{CD} 34^{+} \mathrm{CD} 38^{-} \mathrm{CD} 90^{+}$). We observed that the great majority of hematopoietic progenitors including the most immature $\mathrm{CD} 34^{+} \mathrm{CD} 38^{-}$ $\mathrm{CD}^{+} 0^{+}$cell fraction presented the CALRm (Fig. 2a, b). $C A L R m$ were detectable in more than $50 \%$ of progenitors except in two patients P52 (familial MPN) and P90 (early diagnosis with mild thrombocytosis $(450,000 / \mu \mathrm{L})$ ).
Moreover, the percentage of CALRm HSC-enriched progenitors was comparable to CALRm committed progenitors (Fig. 2c). In four cases (P27, P46, P103, and P169), no detectable CALRwt progenitors were found. We did not detect any homozygous clone in CALRm type 1 ET patients except in one CALRm type $1 \mathrm{MF}$ patient. In contrast, homozygous $C A L R m$ clones were more frequent in CALRm type 2 patients and found in five out of nine ET patients (P28, P50, P185, P187, and P170) (Fig. S3). Of note, we confirmed that these clones were truly 
Fig. 3 CALRm are present at similar VAF in progenitors and mature cells. VAF were calculated in $\mathrm{CD} 34^{+}$

$\mathrm{CD} 38^{-} \mathrm{CD} 90^{+}$and

$\mathrm{CD} 34^{+} \mathrm{CD} 38^{+} \mathrm{CD} 90^{-}$

progenitors and were compared to $\mathrm{VAF}$ in granulocytes

performed by fragment analysis for $10 \mathrm{ET}$ or MF CALR type 1-mutated patients (a), and 8 CALR type 2-mutated patients (b). c VAF for all cell types were calculated for paired data of 4 ET patients with heterozygous type 1 mutation in progenitors, 5 ET patients with a mixture of heterozygous and homozygous type 2 mutation in progenitors and 4 ET patients with heterozygous type 2 mutation in progenitors. Results are the mean \pm SEM $(* P<0.05$; $* * P<0.01$; Tukey's Multiple comparisons test).
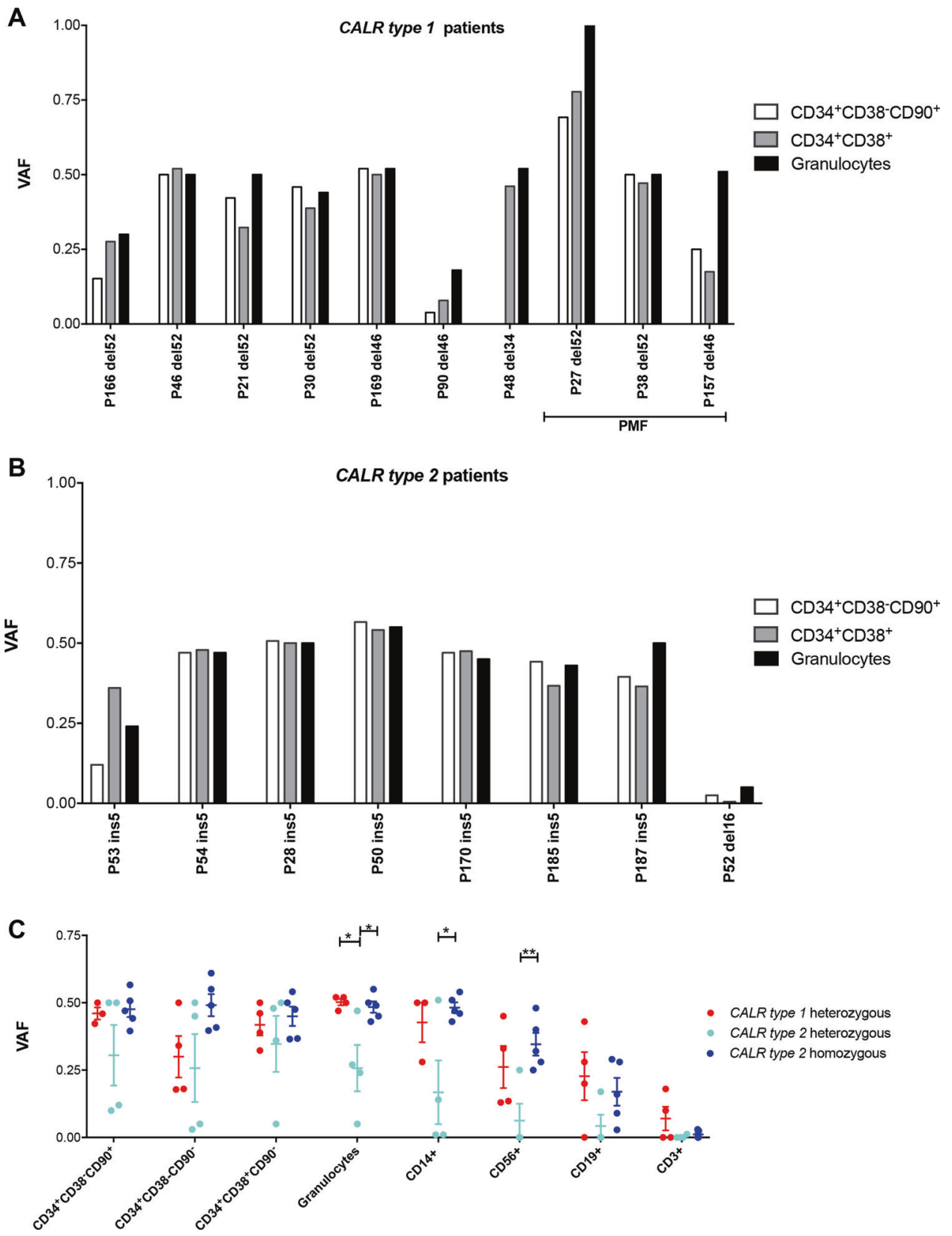

homozygous and not hemizygous, as shown by the relative quantification of copy number of the normal and mutated alleles (Fig. S4).

Altogether, these results show that CALRm (type 1 and 2) are present in the HSC-enriched progenitors and give an advantage from the early stages of hematopoiesis in ET and PMF.

\section{CALRm are present at similar VAF in progenitors and mature granulocytes}

In order to decipher the clonal amplification of the CALRm clone from the progenitor compartment to the mature cells, we calculated the VAF of the $\mathrm{CD} 34^{+} \mathrm{CD} 38^{-} \mathrm{CD} 90^{+}$and
$\mathrm{CD} 34^{+} \mathrm{CD} 38^{+} \mathrm{CD}^{-} 0^{-}$progenitors and compared them to the VAF of granulocytes. In almost all patients with any CALRm, VAF in progenitors was comparable to that found in granulocytes (30-50\%) (Fig. 3a, b). The exception was the patients with a low CALR VAF in granulocytes (P166, P90, P53, and P52), who had an even lower CALR VAF in progenitors suggesting that $C A L R m$ clone amplifies between the HSC-enriched progenitors and the granulocytes. These results were confirmed by directly measuring the $\mathrm{VAF}$ in the $\mathrm{CD} 34^{+} \mathrm{CD} 38^{-} \mathrm{CD} 90^{+}$and $\mathrm{CD} 34^{+} \mathrm{CD} 38^{+}$ $\mathrm{CD}^{-}$cell fraction in five patients. We also analyzed the CALRm VAF in platelets using RNA and compared it to the DNA VAF in granulocytes. Unexpectedly, we found a 
lower CALRm VAF in platelets than in granulocytes (Fig. S5). These results led us to compare the CALRm VAF in $\mathrm{CD}_{3} 4^{+}$cells using DNA or RNA where we observed that the RNA VAF was significantly lower than the DNA VAF for type $2 C A L R$, suggesting that $C A L R m \mathrm{VAF}$ might be underestimated by using RNA instead of DNA.

We tested the impact of CALR status (homozygous or heterozygous) on clonal advantage during myeloid and lymphoid differentiation. We define three groups of patients based on progenitor status: heterozygous type 1, heterozygous type 2, and mixture of heterozygous and homozygous type 2. We used paired data of 4-5 ET patients and calculated the VAF of CALRm for all cell types (early progenitors and late differentiated cells) (Fig. 3c). We observed that heterozygous $C A L R$ type 1 patients harbor similar VAF than homozygous $C A L R$ type 2 patients in progenitors and differentiated cells. In contrast, heterozygous CALR type 2 had a similar VAF than the two other groups in progenitors $\left(\mathrm{CD} 34^{+} \mathrm{CD} 38^{+}\right)$, but with significantly lower VAF in all differentiated cells (Tukey's multiple comparison test: CALR type 1 vs heterozygous $C A L R$ type $2, P<0.01$; and homozygous $C A L R$ type 2 vs heterozygous $C A L R$ type $2, P<0.0001)$.

These results demonstrate that CALRm give a clonal advantage in the HSPC compartment, which spreads in the mature granulocytic cells. Moreover, our results suggest that heterozygous $C A L R m$ type 1 gives a stronger advantage during differentiation than heterozygous CALRm type 2.

\section{CALRm are an early genetic event in ET patients}

Next, we performed a next generation sequencing either by WES or using a 77-gene targeted myeloid panel of 36 CALRm patients mainly in granulocytes. In 15 out of 36 patients (9/19 type 1 and 6/17 type 2), other potential driver mutations were found including PHF6, TET2, SETD1B, DNMT3A, SF3B1, SH2B3, CDH6, and a new PIK3CD mutations (Fig. 4a). In nearly all cases, except P157 PMF patient with a $S F 3 B 1$ mutation, the VAF in granulocytes was higher for $C A L R m$ (type 1 or type 2) than for the other mutations suggesting that $C A L R m$ was the first genetic event (Fig. 4b). To confirm this, we studied the clonal architecture by genotyping each hematopoietic progenitor progeny in five patients. Colonies with only $C A L R m$ were observed and all other mutations were found in CALRm colonies including the ones with SF3B1 mutation (Fig. 4c). These results confirm that CALRm is the first genetic event in most cases.

\section{CALRm induce a strong CFU-MK spontaneous growth}

Since the spontaneous growth and the hypersensitivity to cytokines are a hallmark of $J A K 2 V 617 F$ patients, we tested the impact of CALRm on these features. For that purpose, we cultured the mononuclear cells (MNCs) of 17 patients bearing CALRm (12 type 1 and 5 type 2) and 3 controls from healthy donors in methylcellulose and enumerated the BFU-E, CFU-G/GM/M- and CFU-GEMM-derived colonies. We found an increase in the number of BFU-E and CFU-G/GM/M for type 1 CALRm patients compared to controls (Fig. 5a, c). We did not observe any spontaneous growth of BFU-E or CFU-GEMM in the absence of cytokine in neither the controls nor the CALRm patients (Fig. 5a). However, we detected a variable but not significant spontaneous growth of CFU-G/GM-derived colonies in the absence of cytokine in CALRm patients compared to controls. We then cultured the MNC of 15 CALRm patients (11 type 1 or 4 type 2) and 3 controls from healthy donors in fibrin clot assay and counted the CFU-MK-derived colonies. We found an increase in the number of CFU-MK for both type 1 and 2 CALRm patients as compared to controls (Fig. 5b, c). Moreover, we observed a major spontaneous growth of CFU-MK in the presence of SCF alone or in the absence of any cytokine in CALRm patients (12\% for type 1 and $22 \%$ for type 2) compared to controls (Fig. 5b). Finally, after cell purification and sorting, we confirmed a 4.5-fold increase in the number of $\mathrm{CD} 34^{+}$progenitors $/ \mathrm{mL}$ of blood in $C A L R m$ type 1 patients compared to CALRm type 2 patients (Fig. 5d).

In aggregate, these results show that CALRm induce a strong spontaneous growth of CFU-MK progenitors. Moreover, they show that CALRm type 1 induce a significant increase in total number of progenitors in the blood while CALRm type 2 only increase CFU-MK.

In order to determine the role of JAK2 and PI $3 \mathrm{~K}$ in the spontaneous growth of CFU-MK, we cultured the CD34 + cells from 3 healthy donors (Fig. 5e) and 16 CALRm ET or MF patients in fibrin clot assays with or without cytokine and in the presence of ruxolitinib $(0.5 \mu \mathrm{M})$ or LY294002 (10 $\mu \mathrm{M})$ (Fig. 5f). We observed a significant decrease in the spontaneous CFU-MK growth in the presence of both inhibitors, particularly in absence of TPO. Even if these inhibitors are not specific, these results suggest that the JAK $2 / \mathrm{PI} 3 \mathrm{~K}$ signaling pathways may be important for the CALRm-induced spontaneous growth of CFU-MK.

\section{CALRm induce a constitutive JAK2-STAT-ERK-AKT signaling in $\mathrm{MK}$}

In order to investigate if CALRm could constitutively activate signaling pathways in primary patient cells, we cultured $\mathrm{CD} 34^{+}$progenitors from three control donors, and one $J A K 2 V 617 F$, one CALRdel52 and three other CALRm type 1 patients in $\mathrm{MK}$ culture conditions. No CALRm type 2 patients could be studied due to lack of sufficient amount of 


\section{A}

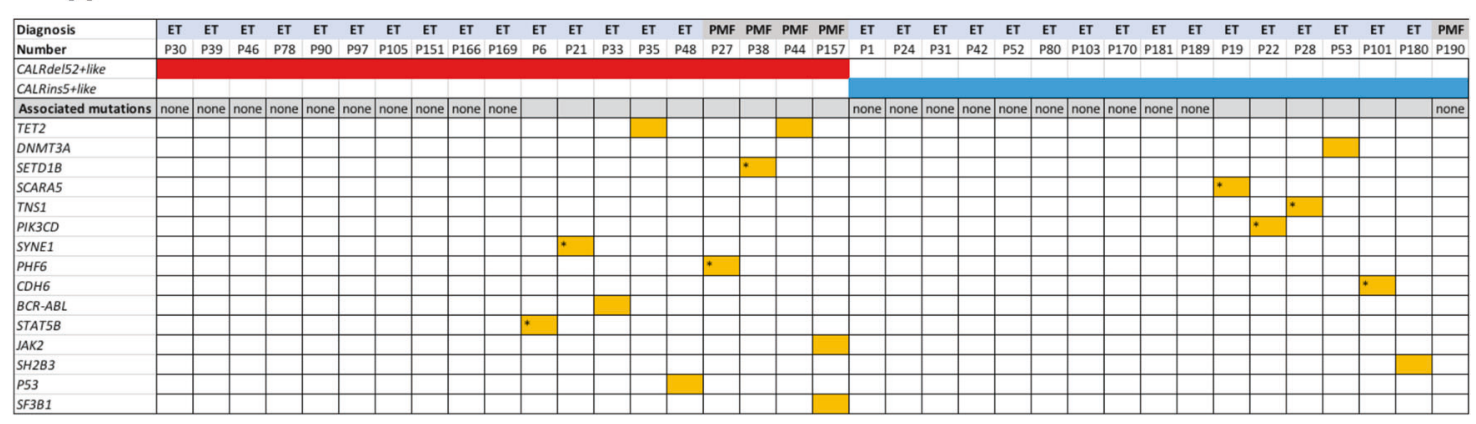

\section{B}
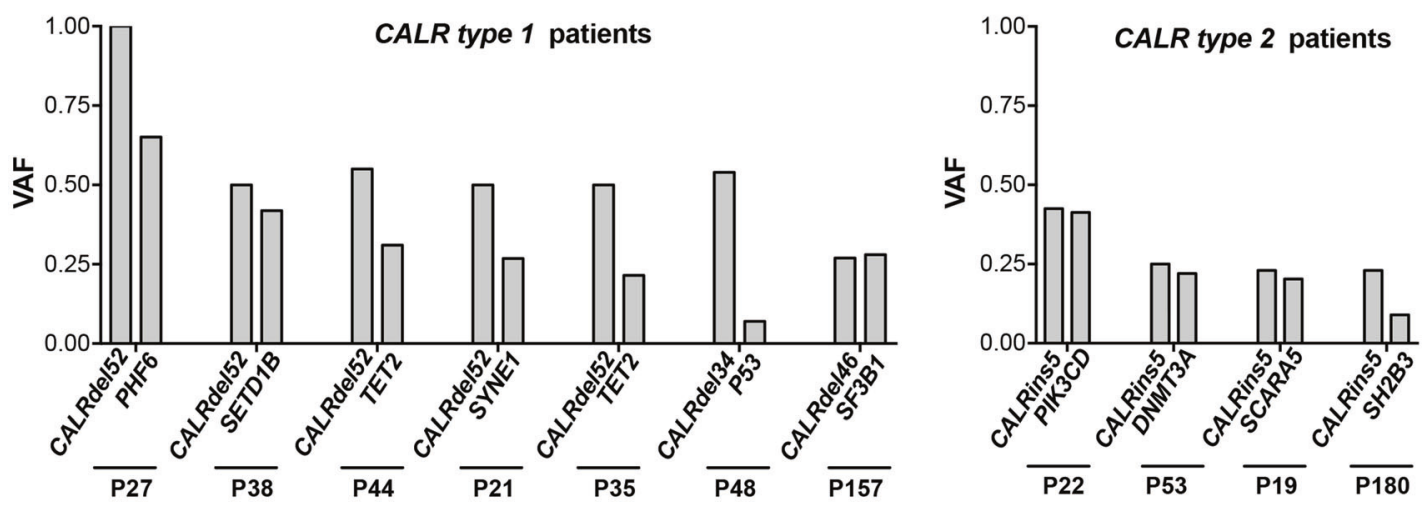

C
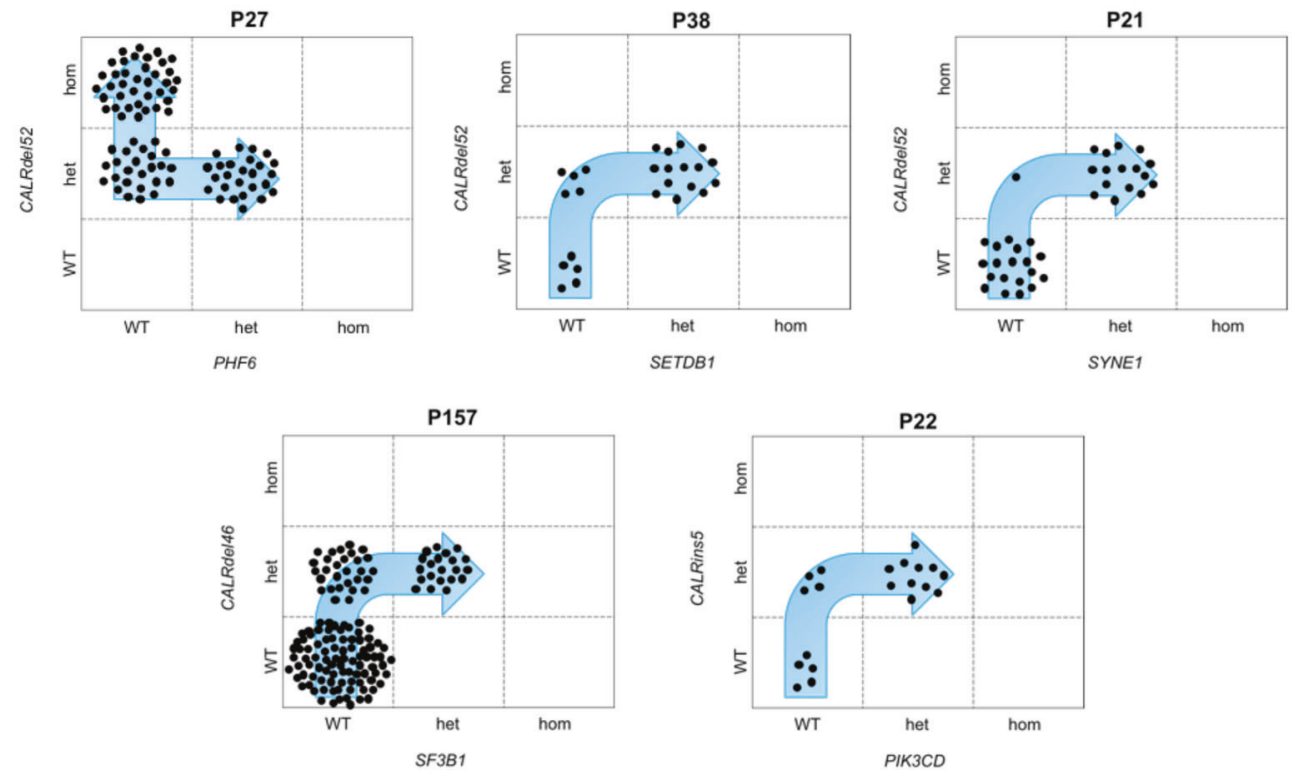

Fig. 4 CALRm is the first event in hematopoiesis. a Mutational status of 36 ET or MF patients with CALR type 1 or 2 mutations were done in granulocytes (31 patients) or whole blood cells (5 patients). Additional associated mutations identified by WES (*) or NGS are indicated. b CALR type 1 or type 2 mutations and associated mutations (PHF6, SETD1B, SYNE1, TET2, SCARA5, PIK3CD, DNMT3A, P53, $S H 2 B 3$, and $S F 3 B 1$ ) VAF were determined in DNA from granulocytes by NGS ( $2 \%$ sensitivity) or WES ( $10 \%$ sensitivity). c Clonal

architecture was performed after sorting $\mathrm{CD} 34^{+} \mathrm{CD} 38^{+}$progenitor cells at single cell level. Each progenitor was grown in serum-free medium with cytokines. 14 days later, each progeny was genotyped for CALRm by conventional PCR analysis and for associated gene mutations by sequencing analysis or allelic discrimination by qPCR $(S F 3 B 1)$. Figures show the number of colonies heterozygous, homozygous or wt for CALRm and SETD1B, SYNE1, PHF6, SF3B1, and $P I K 3 C D$ and (P27, P38, P21, P157 and P22). 

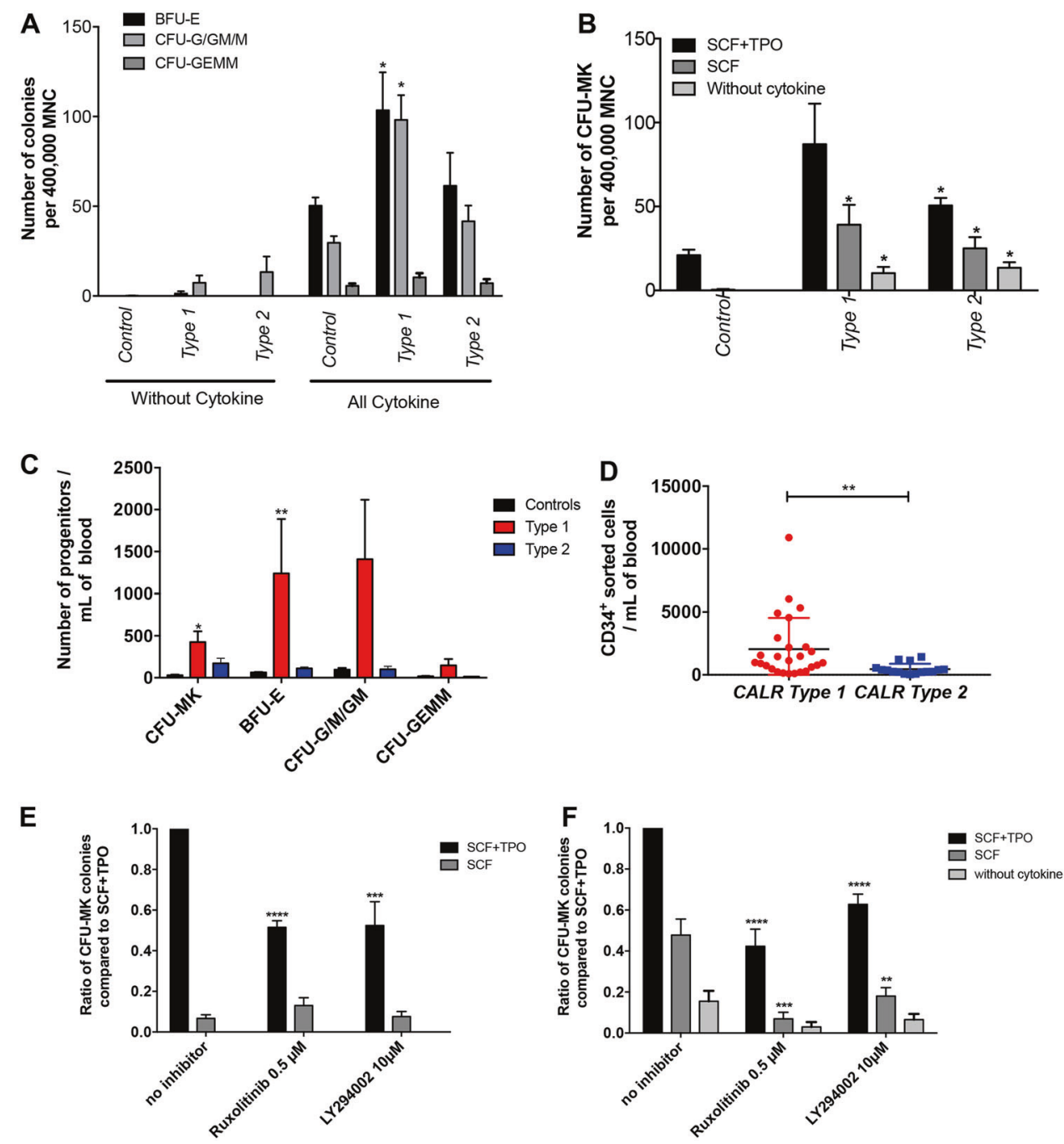

Fig. 5 CALRm induce a spontaneous growth of megakaryocytic progenitors dependent on JAK2 and PI3K. a Monocyte-depleted MNCs $(400,000)$ from 17 CALR-mutated patients (9 ET and 3 PMF type 1 and 5 ET type 2) and 3 healthy donors were cultured in methylcellulose with or without cytokine (SCF, IL-6, IL-3, G-CSF, and EPO) and the BFU-E, CFU-GEMM, CFU-G/GM/M were counted at day 14 . Results are the mean \pm SEM $(* P<0.05$; Mann-Whitney test, two tailed). b MNCs $(400,000)$ from $15 C A L R$-mutated patients (11 type 1 and 4 type 2) and 3 healthy donors were cultured in fibrin clot supplemented with SCF and TPO, SCF alone or without cytokine. CFU-MK colonies were counted in triplicate for each condition after CD41 staining at day 10 of culture. Results are the means of 15 patients \pm SEM $(* P<0.05$; Mann and Whitney test compared to controls, two tailed). c The number of progenitors $/ \mathrm{mL}$ of blood were calculated for BFU-E, CFU-G/GM/M, CFU-GEMM (12 type 1 and 4

type 2) for CFU-MK (10 type 1 and 3 type 2). Results are the mean \pm SEM $\left(* P<0.05\right.$; Mann and Whitney test, two tailed). d CD $34^{+}$progenitors from $C A L R$ type 1 or type 2-mutated patients were purified from MNC by immunomagnetic enrichment followed by cell sorting with an anti-CD34 antibody. Results are the mean \pm SEM of the number of $\mathrm{CD} 34^{+} / \mathrm{mL}$ of blood. Type 1 patients $(n=25)$ and type 2 patients $(n=16)(* * P<0.01$; Mann and Whitney test, two tailed). e/f CD $34^{+}$progenitors from controls (e) or type 1-mutated patients (f) were cultured in fibrin clots with SCF and TPO, with SCF alone or without cytokine and in the absence or presence of ruxolitinib $(0.5 \mu \mathrm{M})$ or LY294002 $(10 \mu \mathrm{M})$. CFU-MK colonies stained with an anti-CD41 antibody were counted at day 10. Spontaneous growth was calculated compared to SCF + TPO. Results represent the mean of the ratio of CFU-MK for each condition compared to CFU-MK cultured in SCF $+\mathrm{TPO} \pm \mathrm{SEM}(* P<0.05$; Mann and Whitney test, two tailed $)$.

$\mathrm{CD} 34^{+}$progenitors. $\mathrm{CD} 41^{+} \mathrm{CD} 42^{+} \mathrm{MK}$ cells were sorted, cytokine and serum-starved and re-stimulated with TPO for 10,30 or $60 \mathrm{~min}$ with or without ruxolitinib. A mild constitutive phosphorylation of STAT5 was observed in a $J A K 2 V 617 F$-positive patient. Similarly, CALRdel52 or CALRdel46 cells showed a constitutive phosphorylation of

STAT3, ERK and AKT compared to controls (Figs. 6 and S6). Moreover, we noticed an important TPO-induced phosphorylation of ERK in the presence of CALR mutants compared to controls. Pretreatment with ruxolitinib led to a decreased phosphorylation of all TPO-induced phosphorylated molecules. 
Fig. 6 CALR type 1 mutation induces constitutive signaling. $\mathrm{CD} 34^{+}$progenitors from three control donors or one $J A K 2 V 617 F$ - or three $C A L R$ mutated patients were cultured in serum-free medium with SCF and TPO. Megakaryocytes $\left(\mathrm{CD} 41^{+} \mathrm{CD} 42^{+}\right)$were serumand cytokine-starved for $16 \mathrm{~h}$ and preincubated or not with ruxolitinib $(0.5 \mu \mathrm{M})$ prior to time-dependent stimulation with $10 \mathrm{ng} / \mathrm{mL}$ TPO. Phosphorylation status of STAT1/3/5, AKT and ERK were analyzed by Western blotting. Expression of $\beta$-Actin was used as loading control. a-d Represent four independent experiments.
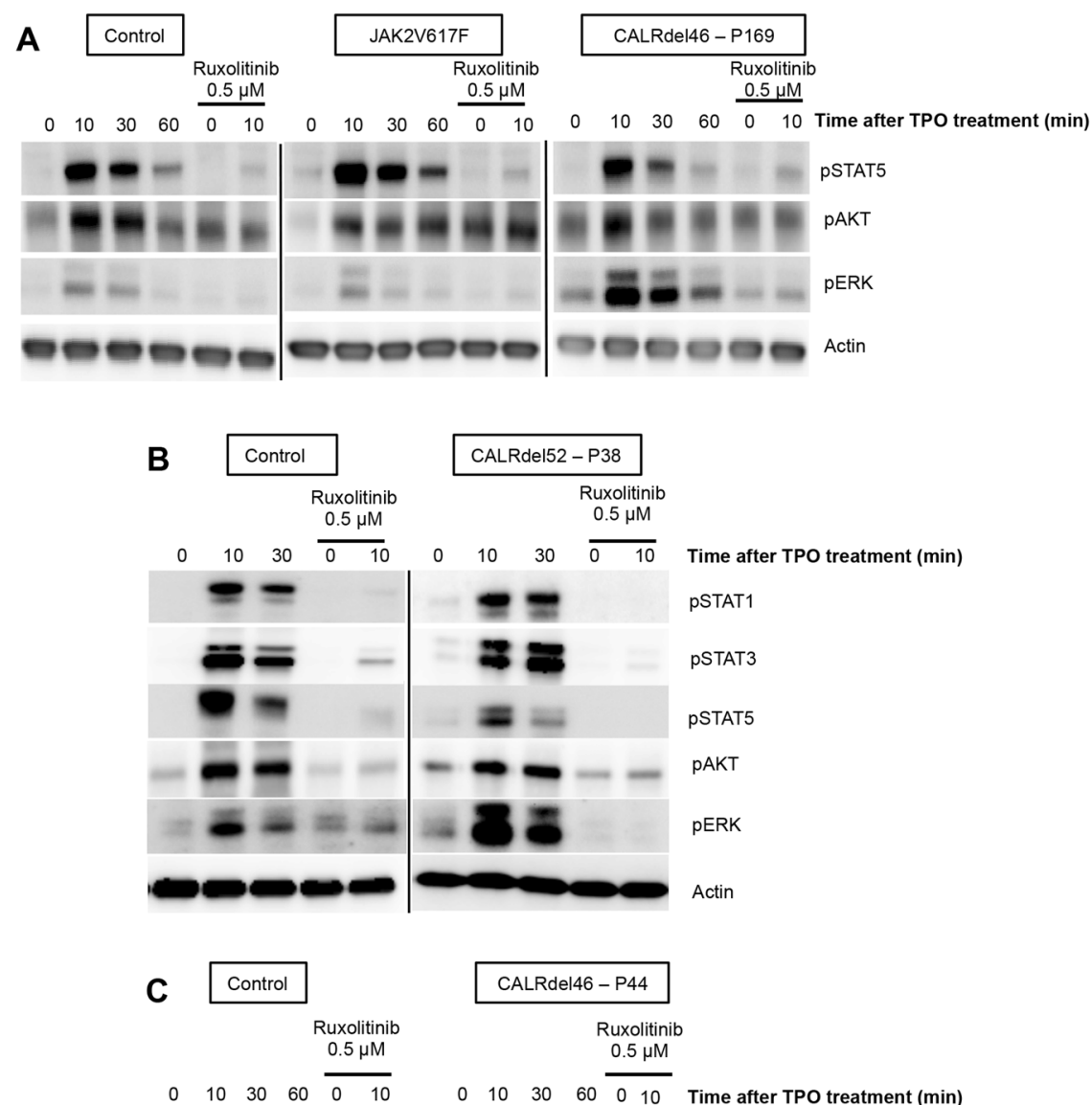
Ruxolitinib
$0.5 \mu \mathrm{M}$

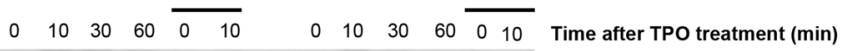

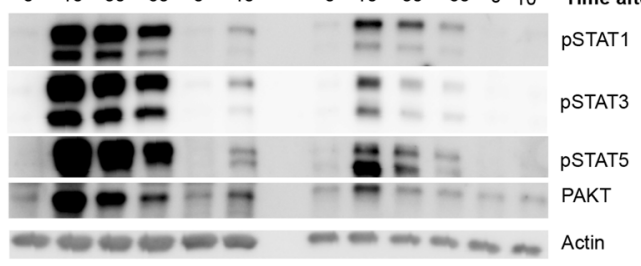

Altogether, these results showed that CALR mutants induce a mild constitutive signaling.

\section{CALRm induce gene deregulation profiles in MK}

In order to investigate if $C A L R m$ can deregulate gene expression profile and to identify specific pathways, CD $34^{+}$ cells from five healthy donors and four ET patients with CALRm (two with type 1 (del46 and del52) and two with type 2 (del13 and del19)) were in vitro cultured in SCF + TPO condition to enable megakaryocytic differentiation. MK were sorted and RNA were submitted to transcriptomic analysis using gene arrays. Deregulated genes found in primary MK were crossed with the one found in murine $\mathrm{Ba} / \mathrm{F} 3$ cell lines overexpressing or not different types of CALRm (type 1 (del52, del34, and del46) and type 2 (del19 and ins5)). The differentially expressed genes from CALRm, CALR type 1, and $C A L R$ type 2 were submitted to gene set enrichment analysis for up- and down-regulated genes using molecular signatures database gene sets (collection Hallmark). We identified very similar pathways in CALRm, CALR type 1 , or CALR type 2 samples, such as STAT5 and the MTORC1 signaling, as expected, but also the interferon gamma response, metabolism regulation (glycolysis, cholesterol, adipogenesis, and fatty acid), the unfolded protein response (UPR) and protein secretion (Figs. 7a and S7). Apoptosis, hypoxia, P53, the TNF $\alpha-N F-\kappa B$ pathways were found downregulated while G2M checkpoint, MYC and E2F target pathways were enriched compared to controls. Of note, adipogenesis and cholesterol homeostasis were negatively enriched in $C A L R$ type 1 and adipogenesis and fatty acid metabolism were positively enriched in $C A L R$ type 2 cells. Using gene set enrichment method selection (enrichKEGG), we found that other expected signaling pathways including PI3K-AKT, calcium, cAMP and cGMP, and actin cytoskeleton were deregulated in the three datasheets (Fig. S8). Then, we performed a more stringent analysis consisting of a pairwise comparison with a classic two-fold change and 
A
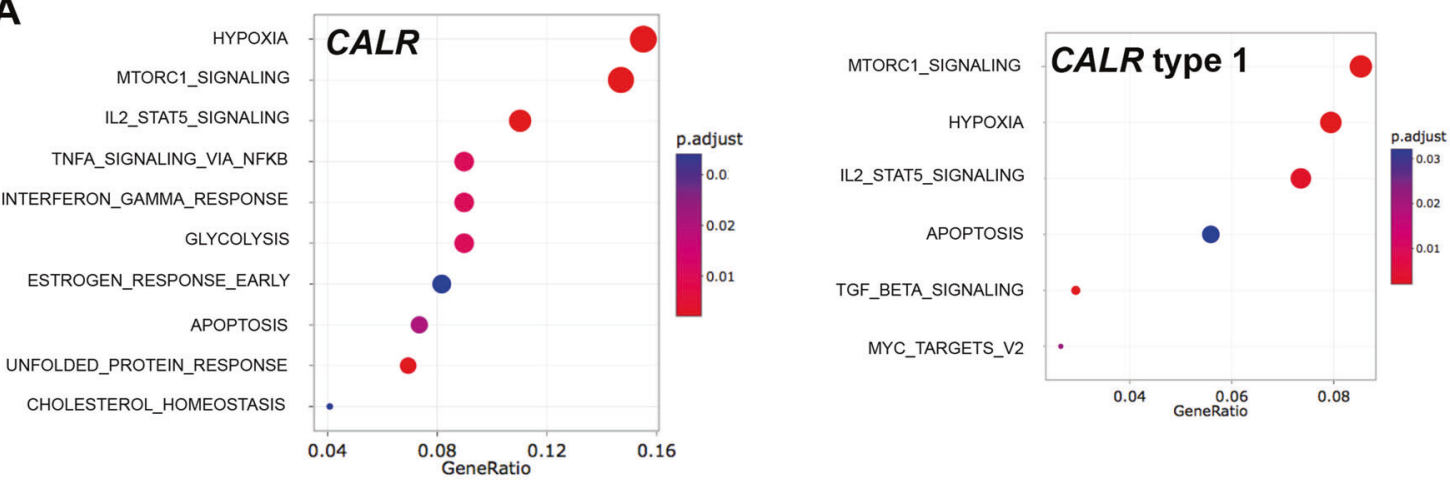

B
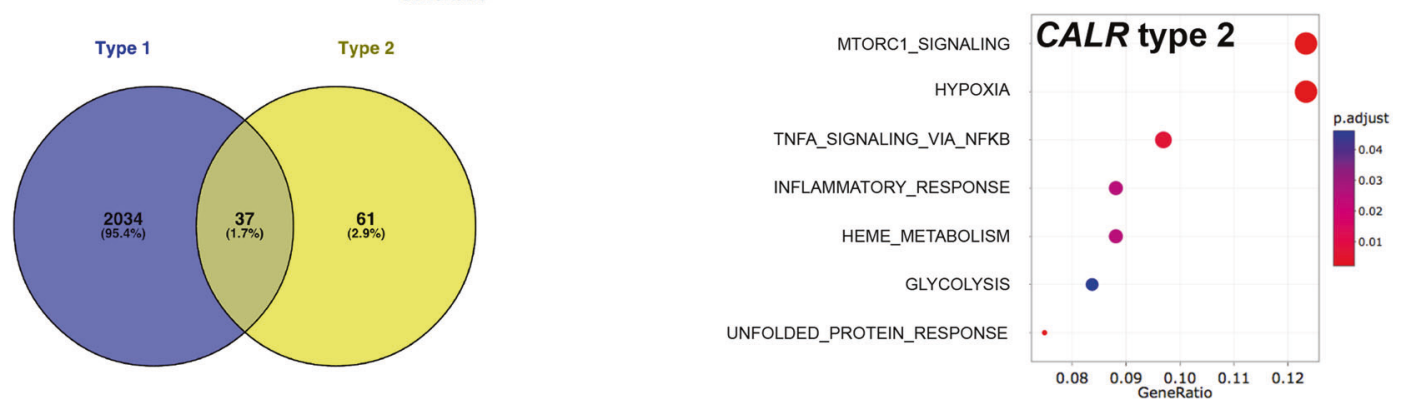

C

$\begin{array}{ll}\text { Category } & \text { Term } \\ \text { BIOCARTA } & \text { uCalpain and friends in Cell spread } \\ \text { BIOCARTA } & \text { TGF beta signaling pathway } \\ \text { BIOCARTA } & \text { Glycolysis Pathwav } \\ \text { BIOCARTA } & \text { Integrin Signaling Pathway } \\ \text { BIOCARTA } & \text { Ras Signaling Pathway } \\ \text { BIOCARTA } & \text { L-10Anti-inflammatory Signaling Pathway }\end{array}$

Genes

7
7
5
10
7
5

\begin{tabular}{c} 
\% of genes \\
\hline 0.4 \\
0.4 \\
0.3 \\
0.6 \\
0.4 \\
0.3
\end{tabular}

\begin{tabular}{|c|c|}
\hline P-Value & Beniamini \\
\hline $1,20 \mathrm{E}-02$ & $9.40 \mathrm{E}-01$ \\
\hline $2.10 \mathrm{E}-02$ & $9.20 \mathrm{E}-01$ \\
\hline $2.50 \mathrm{E}-02$ & $8.70 \mathrm{E}-01$ \\
\hline $3.00 \mathrm{E}-02$ & $8.30 \mathrm{E}-01$ \\
\hline $5.30 \mathrm{E}-02$ & $9.20 \mathrm{E}-01$ \\
\hline $6.40 \mathrm{E}-02$ & $9.30 \mathrm{E}-01$ \\
\hline
\end{tabular}

D
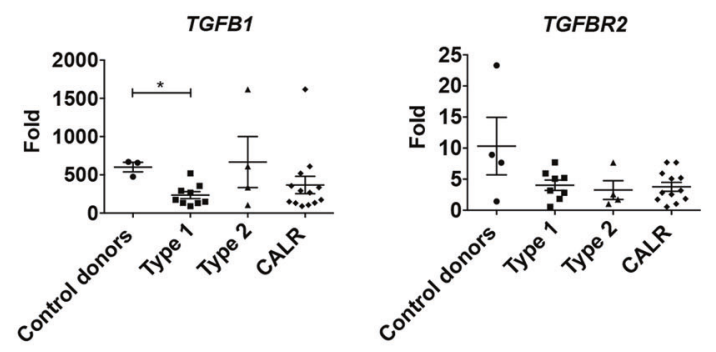

\section{Genes involved in canonical pathway}
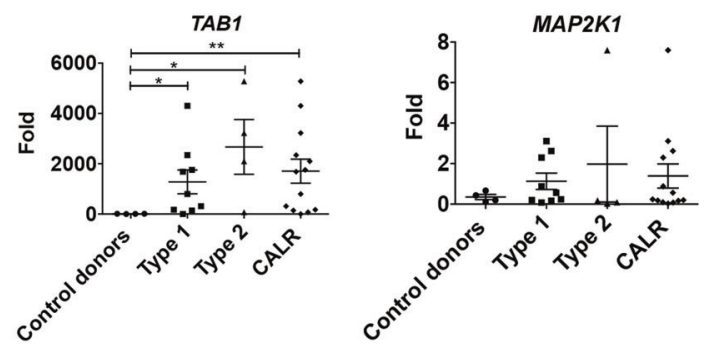

\section{Genes involved in non-canonical pathway}

Fig. 7 CALR type 1 and type 2 mutations induce mild gene expression deregulation in megakaryocytes. $\mathrm{CD} 34^{+}$progenitors from five control donors or two type 1 (P38 and P169) and two type 2 (P42 and P80) CALRm patients were cultured in serum-free medium with SCF and TPO and megakaryocytes (MK) $\left(\mathrm{CD} 14^{-} \mathrm{CD} 41^{+} \mathrm{CD} 42^{+}\right)$ were sorted. Gene expression analysis was conducted. a Gene set enrichment analysis (GSEA) of the hallmark gene sets using the differentially expressed genes between $C A L R \mathrm{wt}$ and $C A L R$ or type 1 or $C A L R$ type 2 . Adjusted $P$ value in red-blue color scale. b Venn

diagram of deregulated genes are shown for CALR type 1 and type 2 . c David functional analysis using functional annotation chart (Biocarta) indicates five pathways. The term (pathways), the number and $\%$ of genes found in the pathways and the $P$ value and the Benjamini adjusted $P$ value are indicated. d Validation of genes involved in TGF $\beta$ signaling in MKs from 3-4 controls, from 9 type 1 CALRmutated patients and 4 type $2 C A L R m$ patients. CALR category regroups type 1 and type $2 C A L R$-mutated patients. Results are the mean \pm SEM $(* P<0.05 ; * * P<0.01$; Mann-Whitney test, two tailed). 
FDR $<0.05$ as a cutoff resulting in a list of differentially expressed genes for $C A L R$ type 1 and type 2 MK. We found 2070 genes deregulated for human $C A L R$ type 1 MK and only 98 genes for human $C A L R$ type $2 \mathrm{MK}$, suggesting either a greater gene deregulation with type 1 than with type 2 mutation or a reduced power analysis for type 2 MK due to low number of samples. Only 37 genes were common to both type 1 and type 2 MK (Fig. 7b). Moreover, David functional analysis using Biocarta indicated five pathways affected in CALR type 1 and none in CALR type 2: mu calpain and friends in cell spread, TGF $\beta$ signaling, glycolysis, integrin signaling, Ras signaling, and IL-10 anti-inflammatory pathway (Figs. 7c and S9). Since the TGF $\beta$ signaling was also specifically deregulated in the GSEA of CALR type $1 \mathrm{MK}$, we focused on this pathway.

We partially validated the TGF $\beta$ pathway with a TGFB1 downregulation in $C A L R m$ type 1 patients only but a $T A B 1$ upregulation in both type 1 and type $2 C A L R m$ patients (Fig. 7d). Altogether, these results suggest a mild transcriptomic deregulation in CALRm MK, eventually more prominent with type 1 than with type 2 mutations.

\section{Discussion}

There is now strong clinical evidence that $C A L R m$ and $J A K 2$ V617F define two different ET entities. CALRm are associated with increased platelet levels, lower leukocyte counts, and hemoglobin levels and risk of thrombosis, as well as the younger occurrence of the disease [8, 9, 21, 24]. From the biological point of view, the VAF is surprisingly much higher in granulocytes for CALRm than for $J A K 2 V 617 F$ although the clinical course of the former patients seems milder $[6,7,21]$. This correlates with a clonal pattern of $\mathrm{X}$ chromosome inactivation in granulocytes in the great majority of female CALRm ET patients and in a minority of $J A K 2 V 617 F$ ET [25].

In this study, we have largely extended these data by showing that $C A L R m$ give a clonal dominance in early steps of hematopoiesis, a result in sharp contrast to what has been demonstrated for JAK2V617F [26-28]. We have shown that $C A L R m$ are present in nearly all progenitors with an HSCenriched phenotype in patients with a VAF around $50 \%$ and in downstream granulocytes with similar VAF as observed by Kjaer et al. [29]. A lower allelic burden in granulocytes generally corresponds to a lower clonal dominance in early and late hematopoietic progenitors. We found only few exceptional cases in this situation either early diagnosis of ET with $(450,000$ platelets $\mu \mathrm{L})$ or case with clear germline predisposition factor that might cooperate with $C A L R m$ for disease development. At least, we could demonstrate that $C A L R m$ target a lympho-myeloid progenitor. Indeed, CALRm were detected in granulocytes, monocytes, B and NK cells and were also detected in certain ET patients in $\mathrm{CD}^{+}$cells with lower VAF according to previous finding [29]. However, here, we pointed out that the CALRm type 1 spreads more easily than the $C A L R m$ type 2 in lymphoid cells. In ET and $\mathrm{PV}$ in contrast to PMF, JAK2V617F can be hardly detected in lymphoid cells [30]. Further experiments are required using xenograft transplantation to demonstrate whether the CALRm clone takes a clonal advantage either in a multipotent lympho/ myeloid cell compartment or in a true long-term reconstituting hematopoietic cell. However, our results are different from a recent report that shows a major increase in VAF between the $\mathrm{CD} 34^{+} \mathrm{CD} 38^{-}$and the $\mathrm{CD} 34^{+} \mathrm{CD} 38^{+}$cell fractions in CALRm ET patients, but not in PMF patients, without discriminating between type 1 and type 2 mutations [31]. This difference can be explained by a potential bias in CALRm detection by RNA versus DNA sequencing as already shown for other mutations [32] and in our study using RNA from platelets. However, the differences between DNA and RNA based assays for CALRm were only observed for the type 2 mutations in progenitors, partially explaining the difference with the work of Nam et al. Presumably, the mRNA of the mutated form can be instable in certain cells particularly in HSC-enriched cells that are more quiescent. In addition, their analyses were only done on the basis of cell surface markers in contrast to our study that was performed on progenitor functional capacities.

Altogether this means that CALRm target a lymphoid/ myeloid progenitor and increase its biological properties at a greater extent for type 1 than for type 2, leading to a clonal advantage, but without further amplification of late stages of differentiation except for the MK lineage (Fig. S10). Thus, we may also speculate that CALR mutants should induce a high HSPC clonal dominance to give rise to a disease. This may explain that homozygous clones in CALRm type 2 patients are frequently observed as this mutation appears to give less clonal advantage than CALRm type 1 . This is opposite to $J A K 2 V 617 F$ that gives a main advantage to all myeloid lineages during differentiation and a low or no advantage to the HSC compartment [33-35]. The presence of other mutations such as in TET2 and DNMT3A is required for $J A K 2 V 617 F$ to give advantage at the early stages of hematopoiesis in ET or PV. Although these epigenetic mutations can be secondary events [36, 37], they usually predate $J A K 2 V 617 F[38,39]$. In contrast, $C A L R m$ are early genetic events in ET with very few additional mutations. As previously reported, we observed associated mutations including TET2, DNMT3A, PHF6, TP53, SH2B3, $S E T D B 1$, and $S F 3 B 1$ as secondary events that may, thus, be associated with disease progression rather than with disease initiation $[6,7,39]$. In contrast, Nam et al. described one case with a SF3B1 mutation that may have preceded $C A L R m$, but it is possible that this patient might have been misdiagnosed as a MPN instead of a refractory anemia with 
ring sideroblasts with thrombocytosis (RARS-T) in which the SF3B1 precedes other mutations [31]. Homozygous $J A K 2 V 617 F$ and MPLW515 mutations due to LOH have been largely reported and are associated with disease phenotypic changes (ET to PV/MF for JAK2V617F and ET to MF for MPLW515) [1, 40, 41]. In half cases, we have found homozygous type 2 CALRm progenitors according to a previous report [6] suggesting that the HSPC clonal dominance should be particularly elevated for this molecular type of disease. In contrast, only one patient with a homozygous type $1 C A L R m$ was found and was associated with disease progression toward MF and leukemia. In contrast, Kjaer's group does not report any homozygous clones in either the $13 \mathrm{CALR} m$ type $1 \mathrm{ET} / \mathrm{PMF}$ or the 4 CALR $m$ type 2 pre-MF [29].

Here, we have mostly used CALRm type 1 MK cells for signaling studies because we recover more $\mathrm{CD} 34^{+}$cells from $C A L R m$ type 1 than for $C A L R m$ type 2 ET patients. Our data suggest a higher mobilization of $\mathrm{CD} 34^{+}$cells by CALRm type 1 than by CALRm type 2 or eventually that type 1 has a greater proliferative impact on $\mathrm{CD} 34^{+}$cells (Fig. 5). Previous studies have afforded evidence that an increased circulating $\mathrm{CD} 4^{+}$cell level is a very early event in MF already detected at the "prefibrotic" stage [42]. Therefore, it is possible that CALRm type $1 \mathrm{ET}$ is a "forme frustre" of MF as JAK2V617F ET is a "forme frustre" of PV [43]. This hypothesis is in agreement with the retroviral mouse model where CALRdel52 induces an ET, which quickly progresses to MF $[15,17]$. This may imply that there is a continuum between a true $C A L R m$ type $1 \mathrm{ET}$ and MF. Accordingly, differences in $C A L R m$ type 1 and 2 have been found in proplatelet formation in primary cells [44]. In contrast, CALRm type 2 ET patients have been shown to harbor higher platelets counts than type 1 ET patients [44]. This could be explained by the presence of homozygous CALRm type $2 \mathrm{MK}$ that can produce larger numbers of platelets than heterozygous CALRm type 1 or $2 \mathrm{MK}$. Finally, our gene expression analysis in MK revealed that $C A L R m$ type 1 might induce a greater gene deregulation than $C A L R m$ type 2 even if this result could also be the consequence of a lack of statistical power due to low number of patients. We propose that $C A L R m$ type 1 might regulate specific pathways such as actin-cytoskeleton, integrin signaling, and inflammation that might be implicated in MF progression [45]. TGF $\beta$ pathway was also found differentially deregulated in type $1 \mathrm{MK}$, with an upregulation of noncanonical genes and a downregulation of canonical genes. Moreover, the two types of $C A L R m$ appear to have opposite effect on the regulation of lipid metabolism. Overall, CALRm MK present an upregulation in pathways involved in cell cycle, but a downregulation of pathways involved in UPR, TNF $\alpha$ via NF- $\mathrm{BB}$ activation and apoptosis including P53 pathway with overlapping genes. Some of the identified pathways (TGF $\beta 1, N F-\kappa B$, and UPR) were also seen to be upregulated in progenitors and granulocytes by gene expression analysis [31, 46]. Finally, the normal interaction between CALR and the proteins involved in ER function (ERP57), UPR (BIP and GRP75), and the cytoskeleton (MYL9) have been shown to be modified by CALRm [47-49].

Finally, we have shown that the MK/platelet phenotype may be due to a TPO independent growth of CFU-MK, as previously reported [50]. In addition, this TPO independent growth is dependent of JAK2 activation, as it was inhibited by ruxolitinib, even at a low dose that only exhibits a mild inhibitory effect on TPO-induced growth. Concomitantly, we observed that CALR type 1 mutants induce a constitutive signaling (particularly on STAT and ERK molecules), which is inhibited by ruxolitinib, as previously shown in cell lines [12-15]. We do not know if all the CALRm effects on HSPC are also dependent of JAK2, but from knockout animals there is strong evidence that JAK2 plays also an important role in HSC biology. In any case, it is interesting that CALRm affect both the HSC and MK/ platelet biology. It has been underscored that MK and HSC have numerous common features with the existence of a MK-biased HSC at the top of HSC hierarchy [51, 52]. TPO, the growth factor regulating platelet production plays also a central role in the regulation of HSC compartment through MPL and JAK2 signaling. Thus, an obvious hypothesis is that $C A L R m$ activate this pathway both in HSC and MK. However, it remains that $J A K 2 V 617 F$, which also activates MPL, appears to have different effects on HSC than CALRm, thus it is possible that CALR mutants may also either use other signaling pathways including calcium signaling and UPR or activate MPL signaling in a different way than JAK2V617F. This comparison will be a powerful approach in the future to characterize the signaling pathways involved in HSC regulation.

Altogether this study demonstrates that CALRm ET is a disease of the HSC and of the MK/platelet lineage, which is different from $J A K 2 V 617 F$ ET. It also indicates a stronger deregulation of hematopoiesis by CALRm type 1 in comparison to $C A L R m$ type 2, leading to a stronger MPN phenotype. It will be important to understand if these two main different biological features sustain the clinical differences between JAK2V617F- and CALRm-ET.

\section{Materials and methods}

\section{Patient cohort}

Blood samples were obtained from Gustave Roussy (Villejuif, France), Saint Louis Hospital (Paris, France), Saint 
Antoine Hospital (Paris, France), Henri Mondor Hospital (Créteil, France), and Brest Hospital (Brest, France) with the agreement from the Comité de Protection des Personnes (CPP) Ile de France IV-Institutional review board (agreement from US Department of Health and Human Services (no. IRB 00003835-Protocol 2015/59-NICB) and Commission Nationale de l'Informatique et des Libertés (authorization \#915663). Written informed consents were obtained in accordance with the Declaration of Helsinki. In most of the patients, the diagnosis was performed according to the WHO recommendation with a bone marrow biopsy (Table S1) [24].

\section{Cell purification and culture}

Peripheral blood from patients was collected in citrate or EDTA tubes. No difference was observed between the two types of anticoagulant except that citrate allows a better platelet recovery. Granulocytes were obtained after hematopoietic cell separation on a ficoll gradient density. Hematopoietic progenitors $\left(\mathrm{CD}^{+} 4^{+}\right)$were isolated from mononuclear cells (MNCs) by immunomagnetic enrichment (Miltenyi, Biotech). T cells $\left(\mathrm{CD}^{-} 6^{-} \mathrm{CD} 14^{-} \mathrm{CD}^{+}\right)$, B cells $\left(\mathrm{CD}^{-} 6^{-} \mathrm{CD} 14^{-} \mathrm{CD} 19^{+}\right)$, monocytes $\left(\mathrm{CD} 14^{+}\right)$, and NK cells $\left(\mathrm{CD} 14^{-} \mathrm{CD}^{+} 6^{+}\right)$were sorted by the Influx flow cytometer (Beckton Dickinson) with a purity $>95 \%$. The following cell fractions $\mathrm{CD} 34^{+} \mathrm{CD} 38^{-} \mathrm{CD}^{+} 0^{+}, \mathrm{CD} 34^{+} \mathrm{CD} 38^{-} \mathrm{CD}^{-} 0^{-}$ and $\mathrm{CD} 34^{+} \mathrm{CD} 38^{+} \mathrm{CD}^{-} 0^{-}$were cloned at 1 cell/well and cultured in presence of a cocktail of human recombinant cytokines containing EPO $(1 \mathrm{U} / \mathrm{mL})$ (Amgen Thousand Oaks, CA), TPO (20 ng/mL) (Kirin, Japan), SCF (25 ng/ mL) (Biovitrum AB, Sweden), IL-3 (10 ng/mL), FLT3-L (10 ng/mL), G-CSF (20 ng/mL), and IL-6 (10 ng/mL) (MiltenyiBiotec). Fourteen days later, individual colonies were plucked and lysed with proteinase $\mathrm{K}$ and $0.2 \%$ Tween 20 (Sigma) at $65^{\circ}$ for $60 \mathrm{~min}$ and $95^{\circ} \mathrm{C}$ for $15 \mathrm{~min}$. DNAs colonies were genotyped with two techniques, a conventional PCR amplification and a quantitative PCR amplification using specific primers for type 1 and type 2 as previously described (Table S2) [53].

\section{Quantification of clonogenic progenitors in semi- solid cultures}

Monocytes were depleted from blood MNC using an immunomagnetic cell sorting system (AutoMacs; MiltenyiBiotec) with anti-CD14 antibody coupled microbeads. Then, the remaining MNCs $\left(4 \times 10^{5}\right.$ cells $/ \mathrm{mL}$ per condition $)$ were seeded in semi-solid cultures either in methycellulose medium (H4230 Methocult, Stem Cell Technologies) without cytokine or supplemented with $25 \mathrm{ng} / \mathrm{mL} \mathrm{SCF}$, $10 \mathrm{ng} / \mathrm{mL}$ IL-3, $10 \mathrm{ng} / \mathrm{mL}$ IL-6, $20 \mathrm{ng} / \mathrm{mL}$ TPO, $1 \mathrm{U} / \mathrm{mL}$ $\mathrm{EPO}$, and $20 \mathrm{ng} / \mathrm{mL}$ G-CSF to quantify erythroid (BFU-E), granulomonocytic (CFU-GM) and granulocyte, erythrocyte, monocyte/macrophage, megakaryocyte (GEMM) progenitors. Cultures were scored after 12-14 days for all colonies. The colonies were plucked using PBS $1 \times$, lysed with proteinase $\mathrm{K}$ and DNA was used for genotyping.

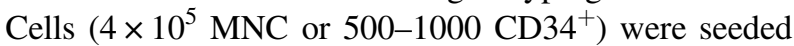
in serum-free fibrin clots either without cytokine or with $25 \mathrm{ng} / \mathrm{mL} \mathrm{SCF}$ and $20 \mathrm{ng} / \mathrm{mL}$ TPO, or SCF alone to quantify megakaryocytic colonies (CFU-MK). The effects of $0.5 \mu \mathrm{M}$ JAK inhibitor (ruxolitinib, Selleckchem) or $10 \mu \mathrm{M}$ LY294002 (PI3K inhibitor, Selleckchem) were tested in these conditions. CFU-MK derived colonies were enumerated at day 10 after labeling by an indirect immuno-alkaline phosphatase staining technique using an anti-CD41a monoclonal antibody (Becton Dickinson, clone HIP8), as previously described [54]. Culture dishes were entirely scanned under an inverted microscope at $\times 4$ or $\times 10$.

\section{Antibodies}

Conjugated monoclonal antibodies against CD34-FITC (\#560942), CD42-PE (\#555473), CD41-APC (\#559777), CD56-APC (\#555518), CD14-FITC (\#555397), CD3PerCP (\#552851), CD19-PE (\#555413), CD38-PE (\#560981), and CD90-APC (\#559869) (Becton Dickinson) were used for cell sorting on an Influx flow cytometer (Becton Dickinson) and characterization of hematopoietic cells analyzed on a FACS Canto I (Becton Dickinson).

\section{Western blot analysis}

$\mathrm{CD}_{3}{ }^{+}$cells from normal donors and patients were cultured in serum-free medium supplemented with $25 \mathrm{ng} / \mathrm{mL} \mathrm{SCF}$ and $10 \mathrm{ng} / \mathrm{mL}$ TPO to induce MK differentiation. MK cells $\left(\mathrm{CD} 41^{+} \mathrm{CD} 42^{+}\right)$were sorted on day 9 , starved for $16-18 \mathrm{~h}$ in serum-free medium without insulin-transferrin in the presence of $0.5 \mu \mathrm{M}$ ruxolitinib or not, then re-stimulated with TPO (10 ng/mL). Each sample was lysed and analyzed by Western blotting. Polyclonal antibodies against phosphorylated forms of STAT1 (Tyr701)(\#9167), STAT3 (Tyr705) (\#9131), STAT5 (Tyr694)(\#9351), ERK1/2 (Thr202/Tyr204) (\#9101), and AKT (Ser473) (\#9271) (Cell signaling) were used to assess the signaling pathways. Monoclonal anti$\beta$-Actin antibody (Sigma) (\#A2228) was used to check the loading. Membranes were revealed using a luminescent image analyzer (Image Quant LAS 4000, GE healthcare).

Acknowledgements This work was funded by grants from the Agence Nationale pour la Recherche (Thrombocytosis, WV), the Ligue Nationale contre le Cancer (équipe labellelisée HR 2016, 2019), the Fondation Laurette Fugain (WV, IP), INCA PLBIO 2016 (IP), by grant " Taxe d'apprentissage" Gustave Roussy-2016 (LS and MEK) and from the INSERM. Labex GR-Ex (IP, WV) is funded by the program "Investissements d'avenir." Support to SNC was from 
Fondation contre le cancer, Salus Sanguinis Action de recherché concertée (ARC) 16/21-073 and WelBio F 44/8/5-MCF/UIG10955. MEK was supported by the SFH (Société française d'hématologie), XC and AT were supported by the university Paris-Diderot (MENRT grant), MM by la Ligue Nationale contre le Cancer, Gustave Roussy Foundation and SFH. GRM was a recipient from allocations doctorales sur domaines cibles (ARDoc, Ile-de-France region). GV was supported by a PhD aspirant fellowship of the Fonds Nationals de la Recherche Scientifique, Belgium. We want to thank the platforms of bioinformatic (Khadija M Diop, Guillaume Meurice and Marc Deloger) and flow cytometry and Edwige Leclercq, Marie-Hélène Courtier for CALR sizing analysis.

\section{Compliance with ethical standards}

Conflict of interest The authors declare that they have no conflict of interest.

Publisher's note Springer Nature remains neutral with regard to jurisdictional claims in published maps and institutional affiliations.

\section{References}

1. James C, Ugo V, Le Couedic JP, Staerk J, Delhommeau F, Lacout $\mathrm{C}$, et al. A unique clonal JAK2 mutation leading to constitutive signalling causes polycythaemia vera. Nature. 2005;434:1144-8.

2. Kralovics R, Passamonti F, Buser AS, Teo SS, Tiedt R, Passweg JR, et al. A gain-of-function mutation of JAK2 in myeloproliferative disorders. N. Engl J Med. 2005;352:1779-90.

3. Cabagnols X, Favale F, Pasquier F, Messaoudi K, Defour JP, Ianotto JC, et al. Presence of atypical thrombopoietin receptor (MPL) mutations in triple-negative essential thrombocythemia patients. Blood. 2016;127:333-42.

4. Milosevic Feenstra JD, Nivarthi H, Gisslinger H, Leroy E, Rumi E, Chachoua I, et al. Whole-exome sequencing identifies novel MPL and JAK2 mutations in triple-negative myeloproliferative neoplasms. Blood. 2016;127:325-32.

5. Pikman Y, Lee BH, Mercher T, McDowell E, Ebert BL, Gozo M, et al. MPLW515L is a novel somatic activating mutation in myelofibrosis with myeloid metaplasia. PLoS Med. 2006;3:e270.

6. Klampfl T, Gisslinger H, Harutyunyan AS, Nivarthi H, Rumi E, Milosevic JD, et al. Somatic mutations of calreticulin in myeloproliferative neoplasms. N Engl J Med. 2013;369:2379-90.

7. Nangalia J, Massie CE, Baxter EJ, Nice FL, Gundem G, Wedge DC, et al. Somatic CALR mutations in myeloproliferative neoplasms with nonmutated JAK2. $\mathrm{N}$ Engl J Med. 2013;369:2391-405.

8. Cabagnols X, Defour JP, Ugo V, Ianotto JC, Mossuz P, Mondet J, et al. Differential association of calreticulin type 1 and type 2 mutations with myelofibrosis and essential thrombocytemia: relevance for disease evolution. Leukemia. 2015;29:249-52.

9. Tefferi A, Wassie EA, Guglielmelli P, Gangat N, Belachew AA, Lasho TL, et al. Type 1 versus Type 2 calreticulin mutations in essential thrombocythemia: a collaborative study of 1027 patients. Am J Hematol. 2014;89:E121-4.

10. Eder-Azanza L, Navarro D, Aranaz P, Novo FJ, Cross NC, Vizmanos JL. Bioinformatic analyses of CALR mutations in myeloproliferative neoplasms support a role in signaling. Leukemia. 2014;28:2106-9.

11. Pietra D, Rumi E, Ferretti VV, Di Buduo CA, Milanesi C, Cavalloni C, et al. Differential clinical effects of different mutation subtypes in CALR-mutant myeloproliferative neoplasms. Leukemia. 2016;30:431-8
12. Araki M, Yang Y, Masubuchi N, Hironaka Y, Takei H, Morishita $\mathrm{S}$, et al. Activation of the thrombopoietin receptor by mutant calreticulin in CALR-mutant myeloproliferative neoplasms. Blood. 2016;127:1307-16.

13. Chachoua I, Pecquet C, El-Khoury M, Nivarthi H, Albu RI, Marty $\mathrm{C}$, et al. Thrombopoietin receptor activation by myeloproliferative neoplasm associated calreticulin mutants. Blood. 2016;127:1325-35.

14. Elf S, Abdelfattah NS, Chen E, Perales-Paton J, Rosen EA, Ko A, et al. Mutant calreticulin requires both its mutant $\mathrm{C}$-terminus and the thrombopoietin receptor for oncogenic transformation. Cancer Discov. 2016;6:368-81.

15. Marty C, Pecquet C, Nivarthi H, El-Khoury M, Chachoua I, Tulliez M, et al. Calreticulin mutants in mice induce an MPLdependent thrombocytosis with frequent progression to myelofibrosis. Blood. 2016;127:1317-24.

16. Balligand T, Achouri Y, Pecquet P, Gaudray G, Colau D, Hug E, et al. Knock-in of Murine Calr del52 induces essential thrombocythemia with slow-rising dominance in mice and reveals key role of Calr Exon9 in Cardiac Development. Leukemia. 2020;34:510-21.

17. Li J, Prins D, Park HJ, Grinfeld J, Gonzalez-Arias C, Loughran S, et al. Mutant calreticulin knockin mice develop thrombocytosis and myelofibrosis without a stem cell self-renewal advantage. Blood. 2018;131:649-61.

18. Shide K, Kameda T, Yamaji T, Sekine M, Inada N, Kamiunten A, et al. Calreticulin mutant mice develop essential thrombocythemia that is ameliorated by the JAK inhibitor ruxolitinib. Leukemia. 2017;31:1136-44.

19. Andrikovics H, Krahling T, Balassa K, Halm G, Bors A, Koszarska M, et al. Distinct clinical characteristics of myeloproliferative neoplasms with calreticulin mutations. Haematologica. 2014;99:1184-90

20. Rotunno G, Mannarelli C, Guglielmelli P, Pacilli A, Pancrazzi A, Pieri $\mathrm{L}$, et al. Impact of calreticulin mutations on clinical and hematological phenotype and outcome in essential thrombocythemia. Blood. 2014;123:1552-5.

21. Rumi E, Pietra D, Ferretti V, Klampfl T, Harutyunyan AS, Milosevic JD, et al. JAK2 or CALR mutation status defines subtypes of essential thrombocythemia with substantially different clinical course and outcomes. Blood. 2014;123:1544-51.

22. Tefferi A, Lasho TL, Finke C, Belachew AA, Wassie EA, Ketterling RP, et al. Type 1 vs type 2 calreticulin mutations in primary myelofibrosis: differences in phenotype and prognostic impact. Leukemia. 2014;28:1568-70.

23. Arber DA, Orazi A, Hasserjian R, Thiele J, Borowitz MJ, Le Beau MM, et al. The 2016 revision to the World Health Organization classification of myeloid neoplasms and acute leukemia. Blood. 2016;127:2391-405.

24. Tefferi A, Thiele J, Vannucchi AM, Barbui T. An overview on CALR and CSF3R mutations and a proposal for revision of WHO diagnostic criteria for myeloproliferative neoplasms. Leukemia. 2014;28:1407-13.

25. Allen C, Lambert JR, Linch DC, Gale RE. X chromosome inactivation analysis reveals a difference in the biology of ET patients with JAK2 and CALR mutations. Blood. 2014;124:2091-3.

26. Dupont S, Masse A, James C, Teyssandier I, Lecluse Y, Larbret F, et al. The JAK2 $617 \mathrm{~V}>\mathrm{F}$ mutation triggers erythropoietin hypersensitivity and terminal erythroid amplification in primary cells from patients with polycythemia vera. Blood. 2007;110:1013-21.

27. Scott LM, Scott MA, Campbell PJ, Green AR. Progenitors homozygous for the V617F mutation occur in most patients with polycythemia vera, but not essential thrombocythemia. Blood. 2006;108:2435-7.

28. Vainchenker W, Delhommeau F, Constantinescu SN, Bernard OA. New mutations and pathogenesis of myeloproliferative neoplasms. Blood. 2011;118:1723-35. 
29. Kjaer L, Holmstrom MO, Cordua S, Andersen MH, Svane IM, Thomassen M, et al. Sorted peripheral blood cells identify CALR mutations in B- and T-lymphocytes. Leuk Lymphoma. 2018;59:973-7.

30. Delhommeau F, Dupont S, Tonetti C, Masse A, Godin I, Le Couedic JP, et al. Evidence that the JAK2 G1849T (V617F) mutation occurs in a lymphomyeloid progenitor in polycythemia vera and idiopathic myelofibrosis. Blood. 2007;109:71-7.

31. Nam AS, Kim KT, Chaligne R, Izzo F, Ang C, Taylor J, et al. Somatic mutations and cell identity linked by Genotyping of Transcriptomes. Nature. 2019;571:355-60.

32. Rodriguez-Meira A, Buck G, Clark SA, Povinelli BJ, Alcolea V, Louka E, et al. Unravelling intratumoral heterogeneity through high-sensitivity single-cell mutational analysis and parallel RNA sequencing. Mol Cell. 2019;73:1292-305. e8.

33. Anand S, Stedham F, Beer P, Gudgin E, Ortmann CA, Bench A, et al. Effects of the JAK2 mutation on the hematopoietic stem and progenitor compartment in human myeloproliferative neoplasms. Blood. 2011;118:177-81.

34. James C, Mazurier F, Dupont S, Chaligne R, Lamrissi-Garcia I, Tulliez M, et al. The hematopoietic stem cell compartment of JAK2V617F-positive myeloproliferative disorders is a reflection of disease heterogeneity. Blood. 2008;112:2429-38.

35. Kent DG, Li J, Tanna H, Fink J, Kirschner K, Pask DC, et al. Selfrenewal of single mouse hematopoietic stem cells is reduced by JAK2V617F without compromising progenitor cell expansion. PLoS Biol. 2013;11:e1001576.

36. Saint-Martin C, Leroy G, Delhommeau F, Panelatti G, Dupont S, James C, et al. Analysis of the ten-eleven translocation 2 (TET2) gene in familial myeloproliferative neoplasms. Blood. 2009;114:1628-32.

37. Ortmann CA, Kent DG, Nangalia J, Silber Y, Wedge DC, Grinfeld $\mathrm{J}$, et al. Effect of mutation order on myeloproliferative neoplasms. N Engl J Med. 2015;372:601-12.

38. Delhommeau F, Dupont S, Della Valle V, James C, Trannoy S, Masse A, et al. Mutation in TET2 in myeloid cancers. N. Engl J Med. 2009;360:2289-301.

39. Lundberg P, Karow A, Nienhold R, Looser R, Hao-Shen H, Nissen I, et al. Clonal evolution and clinical correlates of somatic mutations in myeloproliferative neoplasms. Blood. 2014;123:2220-8.

40. Passamonti F, Rumi E, Pietra D, Elena C, Boveri E, Arcaini L, et al. A prospective study of 338 patients with polycythemia vera: the impact of JAK2 (V617F) allele burden and leukocytosis on fibrotic or leukemic disease transformation and vascular complications. Leukemia. 2010;24:1574-9.

41. Rumi E, Pietra D, Guglielmelli P, Bordoni R, Casetti I, Milanesi C, et al. Acquired copy-neutral loss of heterozygosity of chromosome $1 \mathrm{p}$ as a molecular event associated with marrow fibrosis in MPL-mutated myeloproliferative neoplasms. Blood. 2013;121:4388-95.
42. Barosi G, Rosti V, Bonetti E, Campanelli R, Carolei A, Catarsi P, et al. Evidence that prefibrotic myelofibrosis is aligned along a clinical and biological continuum featuring primary myelofibrosis. PLoS ONE. 2012;7:e35631.

43. Campbell PJ, Scott LM, Buck G, Wheatley K, East CL, Marsden JT, et al. Definition of subtypes of essential thrombocythaemia and relation to polycythaemia vera based on JAK2 V617F mutation status: a prospective study. Lancet. 2005;366:1945-53.

44. Kollmann K, Warsch W, Gonzalez-Arias C, Nice FL, Avezov E, Milburn $\mathrm{J}$, et al. A novel signalling screen demonstrates that CALR mutations activate essential MAPK signalling and facilitate megakaryocyte differentiation. Leukemia. 2017;31:934-44.

45. Chagraoui H, Komura E, Tulliez M, Giraudier S, Vainchenker W, Wendling F. Prominent role of TGF-beta 1 in thrombopoietininduced myelofibrosis in mice. Blood. 2002;100:3495-503.

46. Lau WW, Hannah R, Green AR, Gottgens B. The JAK-STAT signaling pathway is differentially activated in CALR-positive compared with JAK2V617F-positive ET patients. Blood. 2015;125:1679-81.

47. Di Buduo CA, Abbonante V, Marty C, Moccia F, Rumi E, Pietra $\mathrm{D}$, et al. Defective interaction of mutant calreticulin and SOCE in megakaryocytes from patients with myeloproliferative neoplasms. Blood. 2020;135:133-44.

48. Elf S, Abdelfattah NS, Baral AJ, Beeson D, Rivera JF, Ko A, et al. Defining the requirements for the pathogenic interaction between mutant calreticulin and MPL in MPN. Blood. 2018;131:782-6.

49. Pronier E, Cifani P, Merlinsky TR, Berman KB, Somasundara AVH, Rampal RK, et al. Targeting the CALR interactome in myeloproliferative neoplasms. JCI Insight. 2018;3:e122703.

50. Mondet J, Park JH, Menard A, Marzac C, Carillo S, Pourcelot E, et al. Endogenous megakaryocytic colonies underline association between megakaryocytes and calreticulin mutations in essential thrombocythemia. Haematologica. 2015;100:e176-8.

51. Gekas C, Graf T. CD41 expression marks myeloid-biased adult hematopoietic stem cells and increases with age. Blood. 2013;121:4463-72.

52. Sanjuan-Pla A, Macaulay IC, Jensen CT, Woll PS, Luis TC, Mead A, et al. Platelet-biased stem cells reside at the apex of the haematopoietic stem-cell hierarchy. Nature. 2013;502:232-6.

53. Kjaer L, Cordua S, Holmstrom MO, Thomassen M, Kruse TA, Pallisgaard N, et al. Differential dynamics of CALR mutant Allele burden in myeloproliferative neoplasms during Interferon Alfa Treatment. PLoS ONE. 2016;11:e0165336.

54. Debili N, Coulombel L, Croisille L, Katz A, Guichard J, Breton-Gorius $\mathrm{J}$, et al. Characterization of a bipotent erythromegakaryocytic progenitor in human bone marrow. Blood. 1996;88:1284-96. 